\title{
CHEMICAL, MINERALOGICAL AND TEXTURAL CHARACTERIZATION OF RED EARTH FORMATION IN THE NORTHWEST COAST OF SRI LANKA
}

\author{
NADEESHA H. KORALEGEDARA ${ }^{1 *}$, W.L.A.C.I. WEEDAGAMA ${ }^{1,2}$, B. ATHURUPANA ${ }^{1}$, \\ N.W.B. BALASOORIYA ${ }^{1}$, R. CHANDRAJITH ${ }^{1}$, A. SENARATNE ${ }^{1}$ \\ ${ }^{1}$ Department of Geology, University of Peradeniya, Peradeniya, Sri Lanka \\ ${ }^{2}$ Postgraduate Institute of Science, University of Peradeniya, Peradeniya, Sri Lanka \\ *Corresponding author: e-mail: nadeeshak@pdn.ac.lk
}

(Received $5^{\text {th }}$ June 2020; accepted $1^{\text {st }}$ March 2021)

\begin{abstract}
The Red earth (RE) deposit that exists along the northwest coastal belt of Sri Lanka is a significant geological formation. Fine-grained sand coated with iron-aluminum oxides brings the characteristic reddish color and the presence of important heavy minerals such as magnetite, ilmenite, and rutile enhance its economic importance. This work reports the detailed characteristic features of Sri Lankan RE exposed in two different regions; Puttalam (southern part of the deposit) and Mannar (Middle-top part of the deposit). The collected samples were analyzed for particle size distribution, mineralogy, heavy mineral content, geochemistry, and morphology by performing sieve analysis (wet and dry), powder X-ray diffraction, isodynamic magnetic separation, ICP-MS analysis followed by acid digestion and stereo microscopic analysis, respectively. The results indicate two types of clustering of RE in the two regions; moderately sorted $(\sigma=0.8) \mathrm{RE}$ in Puttalam region and poorly sorted $(\sigma=1.3) \mathrm{RE}$ in Mannar region. Rounded quartz grains with bulbous edges and disc-shaped concavities resemble the features of dune sand in Puttalam RE. Sub-angular quartz grains with abundant conchoidal fractures and arcuate steps on grains reflect the influence of high-energy subaqueous depositional environment of Mannar RE. Magnetite and ilmenite are found as the most abundant heavy minerals in both regions. However, significantly higher amounts of heavy minerals, clay minerals (kaolinite) and lighter rare earth elements (La, Ce, Pr, $\mathrm{Nd}, \mathrm{Sm}$ ) are found in Puttalam RE than in Mannar RE. Therefore, though the Sri Lankan RE is considered as a single unit, it has spatial variation in geochemistry, mineralogy and texture.
\end{abstract}

Keywords: Red earth, Aeolian formations, Micro-texture, Heavy minerals, Rare earth elements

\section{INTRODUCTION}

Minerals can play a pivotal role in the economic development of a country. Sri Lanka is abundant with many valuable mineral resources such as phosphate, graphite, mineral sand such as ilmenite, rutile, and garnet, etc. Although some of these resources are utilized effectively, the value of some mineral resources yet to be identified and utilized properly. The red earth (RE) is one such resource, which has not yet been properly investigated for its origin and economic potential. The Red earth formation, outspread approximately $1 / 3$ of the northwestern and northeastern coastline between Puttalam to Mulativu, is one of the most distinct members of the Quaternary period (Fig. 1). In most areas, the $\mathrm{RE}$ occurs as narrow, elongated dunes or domes aligned in the North - South direction overlain the Miocene limestone formation. The average height of these ridges is about $5-10 \mathrm{~m}$, but in some locations such as Aruwakkalu area in Puttalam District, it exceeds over $30 \mathrm{~m}$. The RE formation is assumed to be about $1 \mathrm{~km}$ wide from the coast. However, the quantification details of the RE deposit has not been reported to date. The generalized stratigraphic profile indicates that the RE formation overlies the Miocene age limestone (Fig. 2). However, the thickness of different layers and the composition varied spatially. At present, RE is removed and used as a filling material to cover the open mine pits of the Aruwakkalu limestone quarry. Other than that RE is not utilized for any beneficial purpose, despite the presence of many heavy mineral (Dahanayake and Jayawardhana, 1979, Wallace, 2016). 


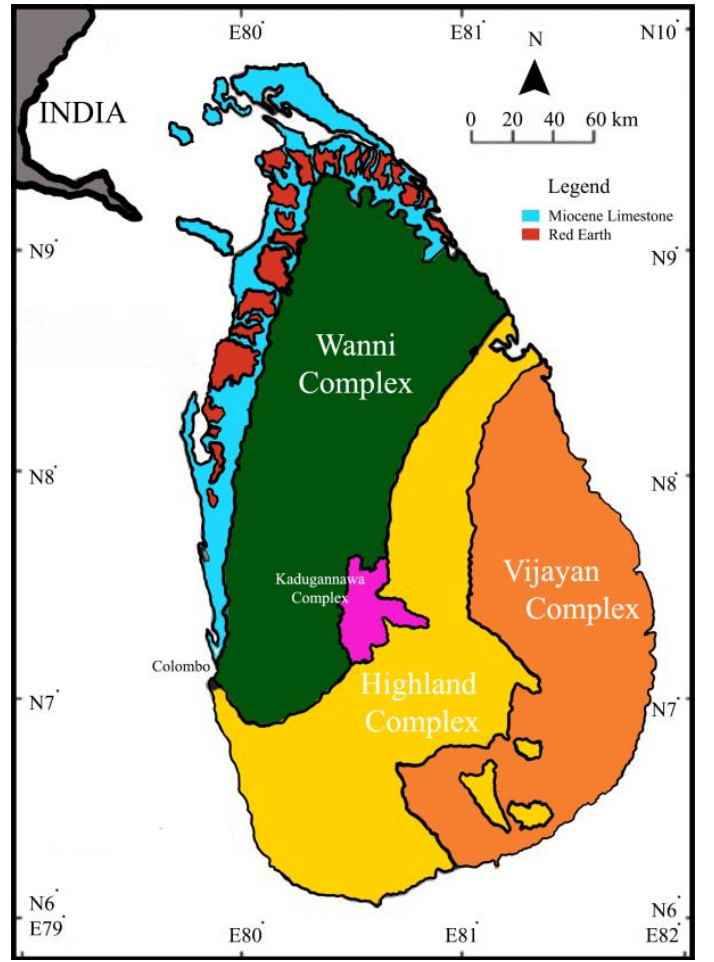

Fig. 1 Red earth deposits of Sri Lanka (marked in red color)

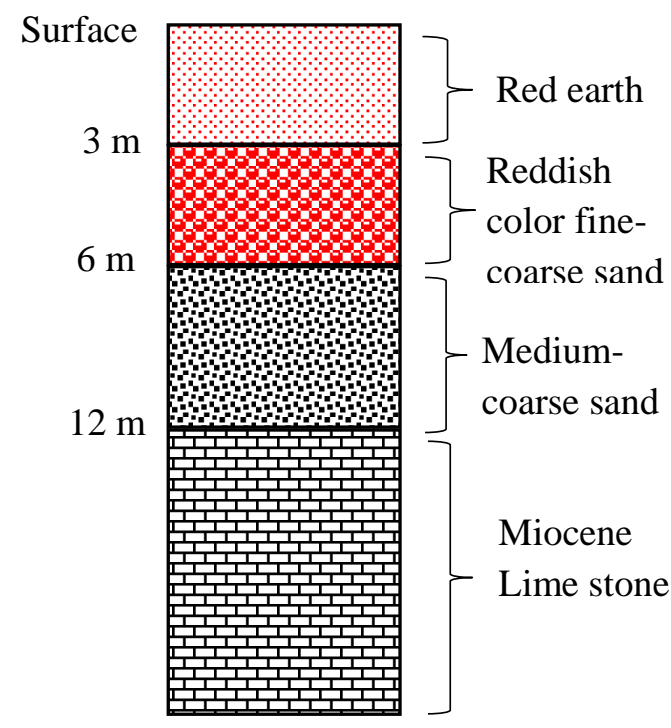

Fig. 2 Generalized stratigraphic profile of Sri Lankan red earth

considered as a unique geologic formation, only a few studies have been carried out to investigate these deposits in detail (Dahanayake \& Jayawardena, 1979, Vithanage et al., 2006, USGS, 2014, Wallace, 2016, Reuter et al., 2020).
While Dahanayake \& Jayawardena (1979) published the geology and characteristic features of RE formation, Wallace et al., 2016 described the mineral distribution and economic potential of Sri Lankan RE in Aruwakkalu area. In 2014, the US Geological Survey has reported the average heavy mineral content of RE is as $8.2 \%$. While ilmenite takes the major portion of that heavy mineral content $(67 \%)$, other economically important minerals such as rutile and zircon cover about $4 \%$. The RE mainly comprised of $\mathrm{Fe}$ coated quartz in a clayey matrix and $\mathrm{Fe}_{2} \mathrm{O}_{3}$ and $\mathrm{Al}_{2} \mathrm{O}_{3}$ coating reflects the characteristic reddishbrown color (Vithanage et al., 2006). In addition to the Fe-oxide coating, magnetite and hematite are found as main Fe-bearing minerals in RE. It is assumed that both Teri sand formation on the southwest coast of Tamil Nadu, India, and Sri Lankan RE on the northwest coast may possess a similar history of formation due to characteristic similarities between the two formations (Reuter et al., 2020). However, the origin of Sri Lankan $\mathrm{RE}$ is not yet resolved. Besides the aforementioned studies, a few studies have focused on the application of RE for removal of contaminants such as As (Vithanage et al., 2006, 2007, Rajapaksha et al., 2011), Pb (Mahatantila et al., 2011), Cd (Mahatantila et al., 2012), Cr (Pathberiya et al., 2019; Nikagolla et al., 2012) from aqueous media. However, none of these studies has attempted to investigate the spatial variation of chemistry and mineralogy of the RE deposit in Sri Lanka. Therefore, the present study attempts to investigate the spatial variations in geochemistry, mineralogy, and textural features of RE formations in Puttalam and Mannar Districts of Sri Lanka.

\section{MATERIALS AND METHODS}

Red Earth samples were collected from nine (9) locations in Puttalam and Mannar Districts of Sri Lanka (Fig. 3). Samples were retrieved from every $30 \mathrm{~cm}$ interval up to about 2-3 $\mathrm{m}$ below the surface using a hand auger. The particle size distribution of RE recovered from different depths was analyzed using sieve analysis. Weight percentages of clay and silt fractions were obtained by the pipette analysis. The qualitative assessment of mineralogical composition was carried out using a powder X-ray diffractometer (XRD). Clay fraction that separated by the pipette method was also analyzed by XRD. Frantz isodynamic magnetic separator was used to carry out a quantitative analysis of heavy minerals in 


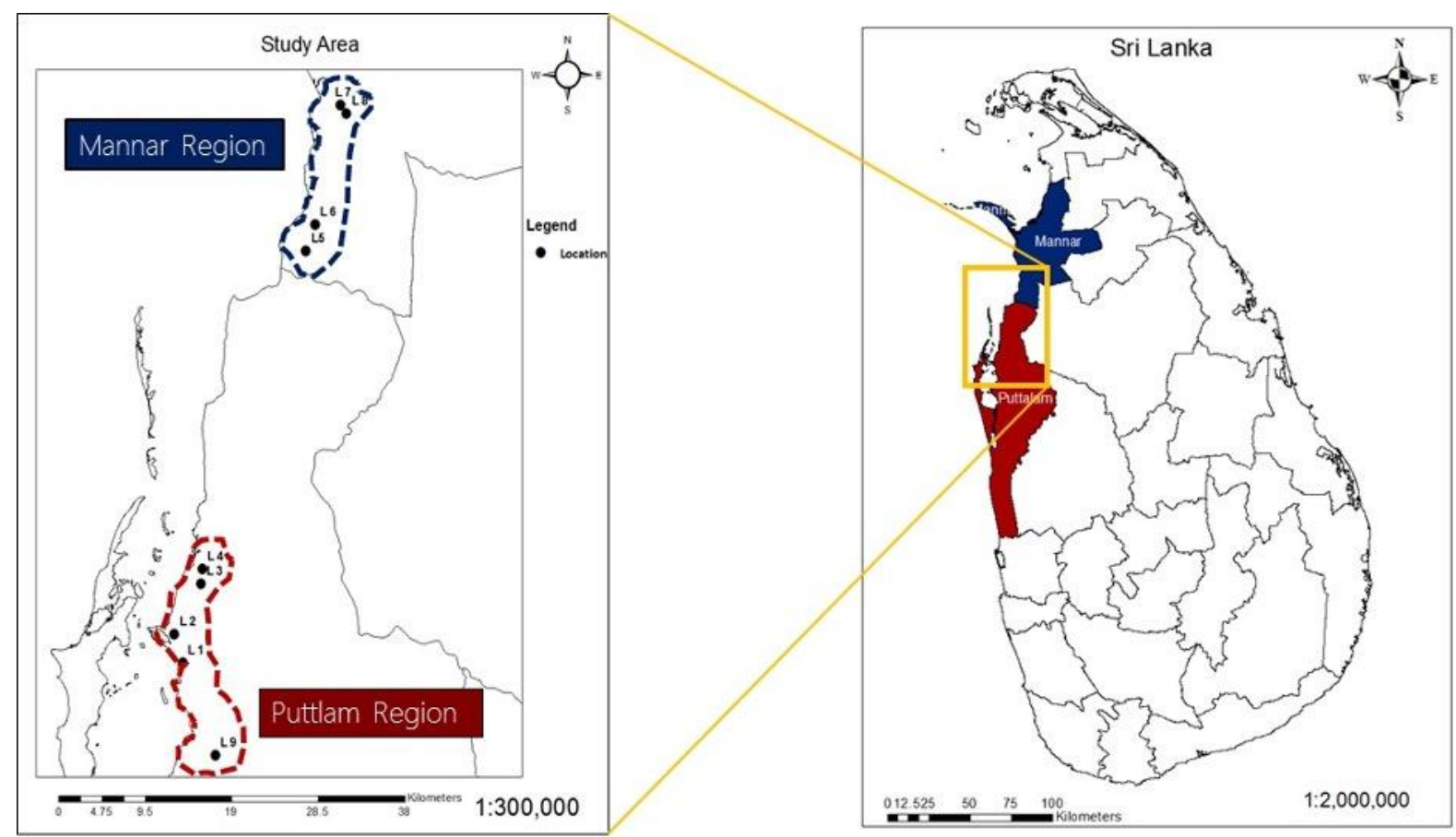

Fig. 3 Study area and sampling locations

samples after removing the loosely bound clay size particles around the grains by washing with deionized water. Microwave aided acid digestion was performed following the EPA-3015 protocol, and resultant solutions were quantified using Inductively Coupled Plasma Mass Spectrometry (Thermo Scientific ICapQ). Textural features of mineral grains were observed using the stereomicroscope.

\section{RESULTS \& DISCUSSION}

\section{Mineral Composition of Red Earth}

As indicated by the XRD analysis, the main minerals in Sri Lankan RE are quartz, magnetite, ilmenite, and clay minerals such as kaolinite (Fig. 4). Sieve analysis along with the magnetic separation revealed the average relative proportions of each mineral constituent of RE in Puttalam and Mannar region as given in Table 1. Quartz is the main constituent of RE in both areas. Scanning Electron Microscopic (SEM) analysis confirmed that most of these grains are coated with $\mathrm{Fe}$ - and $\mathrm{Al}$-oxides. In addition to the coating, fractures of the quartz grains were also filled with these oxides (Fig. 5a). Magnetite and ilmenite were the main Fe-bearing minerals found in RE samples. However, compared to the Mannar region, RE in Puttalam area contained a significantly higher amount of both magnetite and ilmenite. While almost equal amounts of magnetite $(\sim 1 \%)$ and ilmenite $(\sim 1 \%)$ were observed in Mannar RE, relatively higher amounts of magnetite ( $\sim 9 \%)$ and ilmenite $(\sim 6 \%)$ were observed in Puttalam samples. Irrespective of the region, both magnetite and ilmenite grains are covered with $\mathrm{Fe}-\mathrm{Al}$ oxide coating similar to the one found on quartz grains (Fig. 5 b). The origin of magnetite and ilmenite in RE may be detrital and the fluvial systems may have brought them and deposited in RE as stated in Deraniyagala, 1968. The variance in the heavy mineral distribution in sampling regions could be attributed to the difference in drainage densities, viz lesser number of river flows into the Mannar area compared to the Puttalam region. Kala Oya, Mi Oya, and Deduru Oya rivers supply materials to the Puttalam area but only Malwathu Oya river provides terrestrial flux to the Mannar region. In sediment production among the main rivers of Sri Lanka, Deduru Oya and Kala Oya rivers are ranked in the $9^{\text {th }}$ and $10^{\text {th }}$ positions, respectively (Swan, 1983). In addition, the formation of Puttalam lagoon and Kalpitiya barrier bars may have facilitated the preservation of heavy minerals in Puttalam region (Wallace et al., 2016). 


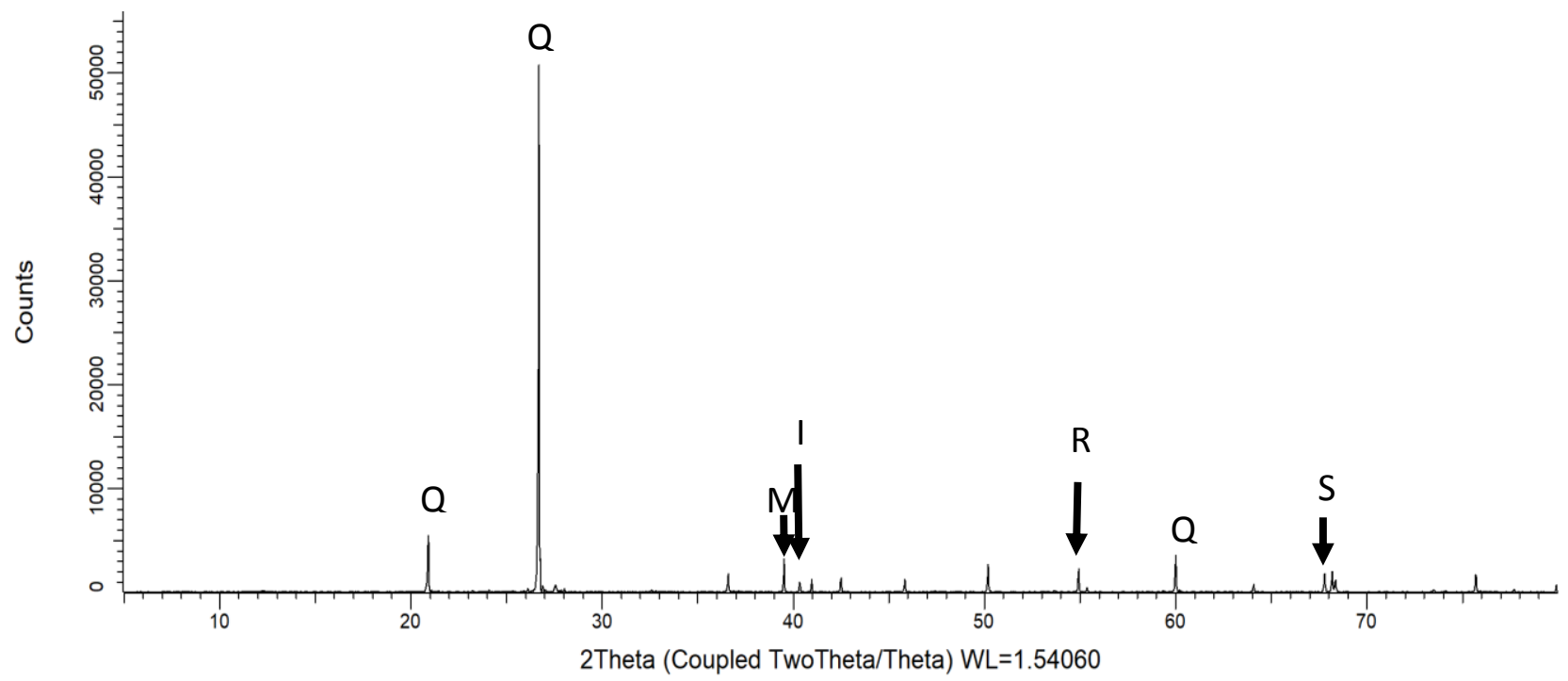

Fig. $4 X$-Ray diffraction analysis of a red earth sample from Puttalam region ( $Q=Q u a r t z, M=$ Magnetite, $I=$ Ilmenite, $R=$ Rutile, $S=$ Spinel)

Table 1 Composition of red earth in Puttalam and Mannar region

\begin{tabular}{lllll}
\hline \multirow{2}{*}{ Mineral } & \multicolumn{4}{c}{ Weight (\%) } \\
\cline { 2 - 5 } & \multicolumn{3}{c}{ Puttalam } & Mannar \\
\cline { 2 - 5 } & Average & STDV & Average & STDV \\
\hline Quartz & 84 & 3.95 & 97 & 3.68 \\
Magnetite & 9 & 0.97 & 0.8 & 0.22 \\
Ilmenite & 6 & 3.14 & 0.9 & 0.63 \\
Clay (Kaolinite) & 0.6 & - & unquantifiable & - \\
\hline
\end{tabular}

In addition to magnetite and ilmenite, monazite and zircon were found in non-quantifiable amounts. Even though the XRD data revealed the presence of rutile in RE, the separation by isodynamic magnetic separator was not successful, possibly due to the Fe-oxide coating, which affects the magnetic property of the minerals (Bheemalingeswara, 1995). Wallace 2016 has also reported a similar mineralogical composition in the Aruwakkalu quarry site.

Relatively higher clay content was observed in Puttalam RE formation (0.6\%) compared to that of in the Mannar. The origin of clay can be either detrital or in-situ. As the degree of weathering is enhanced by arid conditions, high temperature, low humidity, and alternate wet and dry conditions, differences in the two regions may have affected the observed discrepancy in clay content. Further, the influence of fluvial activities may also have caused the difference in clay content of the RE in two studied regions.

\section{Chemical Composition}

The high Fe content $(1.34 \%)$ of RE resembled the presence of Fe-bearing minerals. The rare earth element (REE) distribution in RE formations was assessed to identify the potential of utilizing RE as a source of economically important. A significant difference was observed among the REE distribution in samples from Puttalam to 

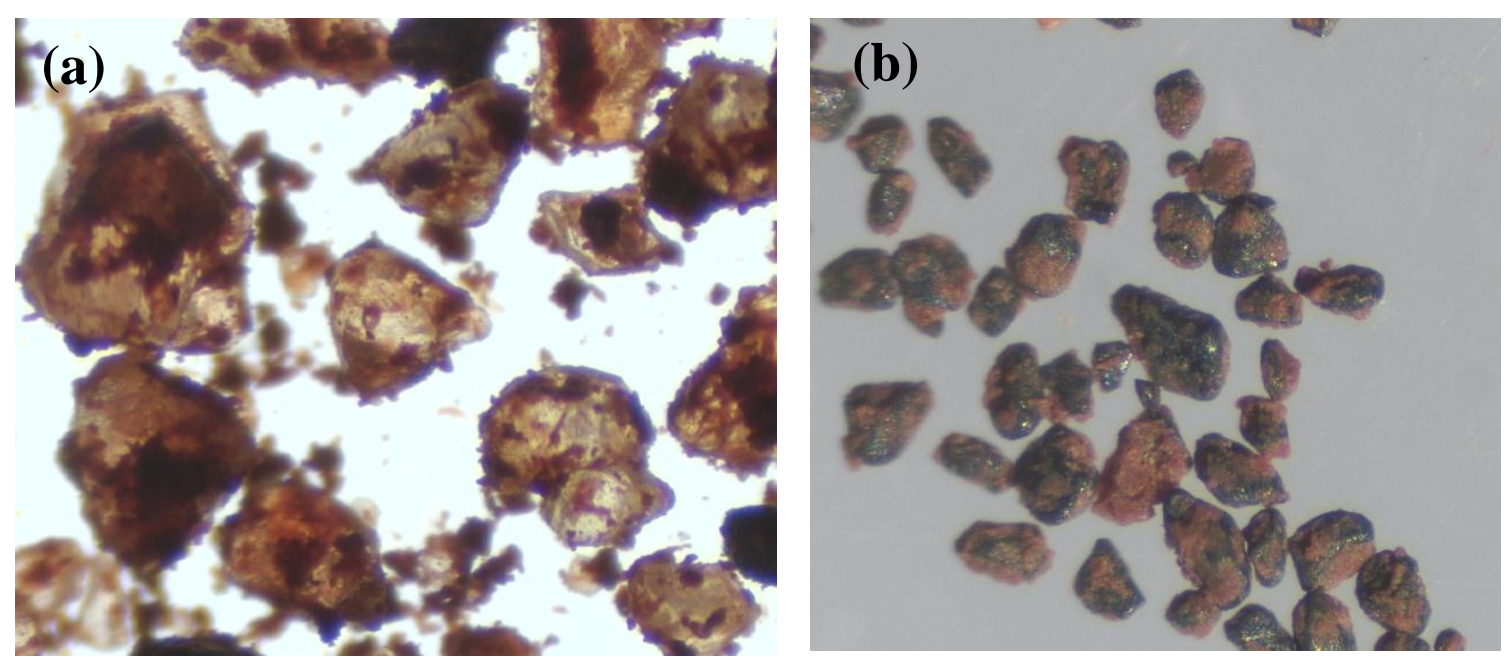

Fig. 5 (a) Quartz grains with Fe-Al oxide coating and fractures filled with Fe-Al oxides, (b) Magnetite and Ilmenite coated with Fe-Al oxides

and Mannar region. However, no significant difference was observed in major element distribution. Considerably higher amounts of light REE ( $\mathrm{La}, \mathrm{Ce}, \mathrm{Pr}, \mathrm{Nd}, \mathrm{Sm}, \mathrm{Gd}$ ) were observed in Puttalam samples compared to that of in Mannar (Fig. 6). This can be mainly attributed to the presence of higher concentrations of heavy minerals and clay minerals in Puttalam samples compared to the Mannar samples.

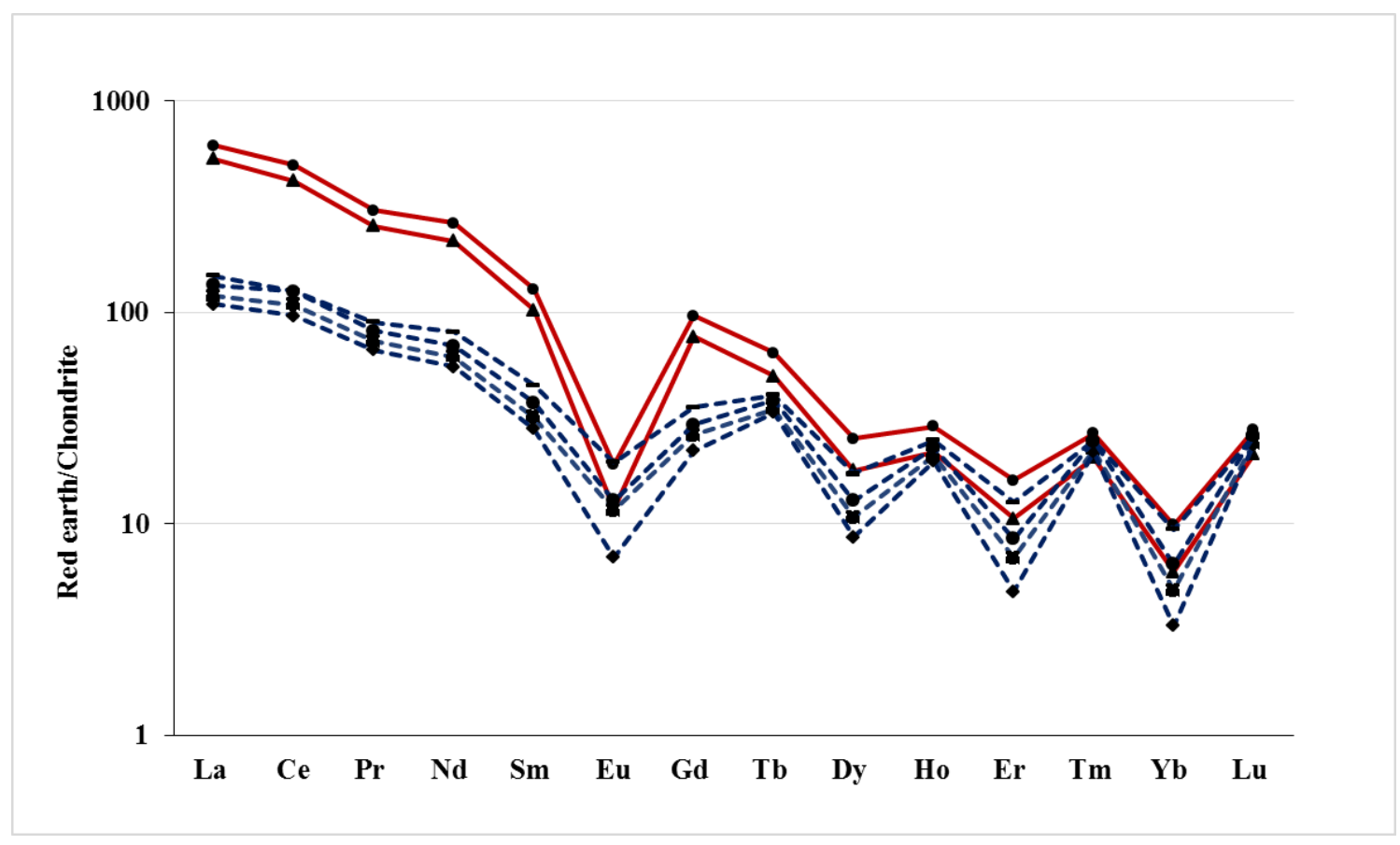

Fig. 6 Chondrite normalized rare earth element (REE) distribution pattern in Puttalam (solid line) and Mannar (dashed line) red earth 


\section{Morphology and Textural Characteristics}

Grain morphology and textural features have been widely used to interpret the provenance of geological formations (Itamiya et al., 2019, Bernet and Basset, 2005). Since the origin of the Sri Lankan RE deposit is yet to be confirmed, the morphological features of grains in RE could provide an insight into the origin. Although it is widely believed that RE in the northwest coast is of aeolian in origin (Dahanayake and Jayawardhane, 1979, Singhvi et al., 1986, Wallace et al., 2016), certain characteristics such as the presence of basal ferruginous gravels indicates the influence of fluvial activity (Reuter et al., 2020).

\section{Grain size}

Both Puttalam and Mannar samples showed a uni-modal grain distribution pattern (Fig. 7) with the mean grain size of $0.30 \mathrm{~mm}$ and $0.33 \mathrm{~mm}$, respectively.

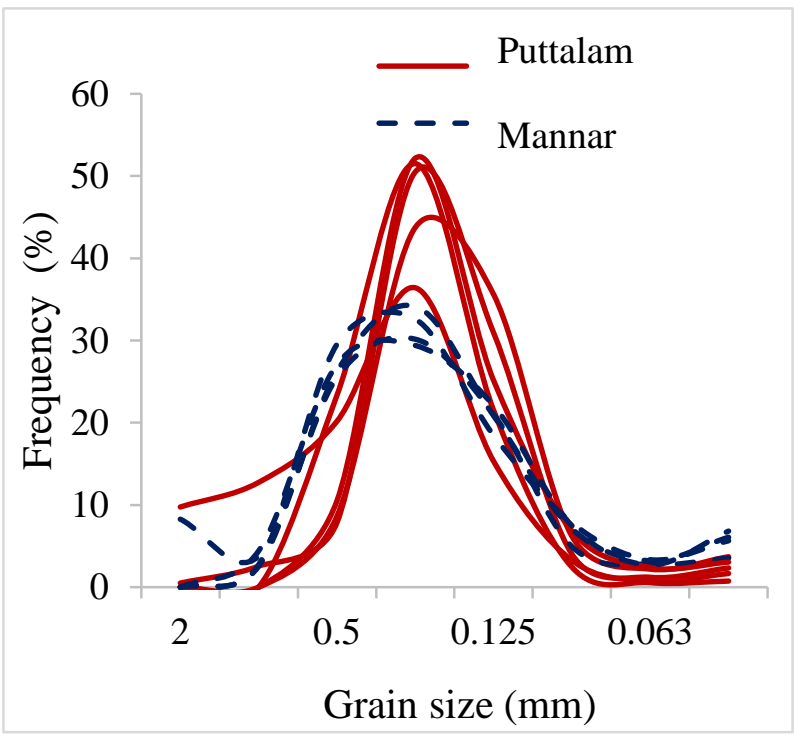

Fig. 7 Frequency distribution curves showing uni-modal distribution of grains of red earth of Puttalam (solid lines) and Mannar (dashed lines) regions

According to the particle size distribution analysis, Puttalam samples contained more fine and medium sand compared to that of in Mannar (Table 2). The northwestern coast of Sri Lanka faces the most intense and strongest wind currents during the southwest monsoon season (Swan 1983). In addition, northerly wind blowing from the Indian subcontinent can also affect the sedimentation pattern of the northwest coast. The northwest coast has relatively little influence from NE monsoon compared to SW monsoon. Relatively higher fine-medium sand percentage in Puttalam RE compared to that of in Mannar could be a result of high energy wind, which can transfer sand and silt particles from southern and western coasts towards north leaving coarser grains proximal to the origin. The coarse sand fraction (1-2 mm) was higher (30.4\%) in Mannar RE compared to that of in Puttalam (14.9\%). This may probably due to the transport of sediment from the Indian subcontinent (Sundararajan and Srinivasalu, 2010, Reuter et al., 2020).

Table 2 Sand size particle distribution in Puttalam and Mannar red earth samples

\begin{tabular}{lcc}
\hline & \multicolumn{2}{c}{ Average Weight (\%) } \\
\cline { 2 - 3 } & Puttalam & Mannar \\
\hline $\begin{array}{l}\text { Coarse sand } \\
(0.5-2 \mathrm{~mm})\end{array}$ & $14.9( \pm 6.7)$ & $30.4( \pm 1.7)$ \\
$\begin{array}{l}\text { Medium sand } \\
(0.25-0.5 \mathrm{~mm})\end{array}$ & $48.1( \pm 3.6)$ & $31.6( \pm 2.1)$ \\
$\begin{array}{l}\text { Fine sand } \\
(0.063-0.25 \mathrm{~mm})\end{array}$ & $34.1( \pm 8.2)$ & $30.4( \pm 1.6)$ \\
\hline *standard deviations are given within brackets & \\
\multirow{2}{\text{Grainsorting}}{} & &
\end{tabular}

The degree of sorting can be expressed statistically based on sieve analysis data or visually with microscopic images. According to the statistical analysis, Puttalam RE $(\sigma=0.8)$ can be categorized as moderately sorted whereas Mannar samples $(\sigma=1.3)$ as poorly sorted (Blott and Pye, 2001). Wallace et al, 2016 also has categorized the Aruwakkalu RE are as moderately sorted. Microscopic observations of samples confirmed the results of statistical analysis (Fig. 8). 

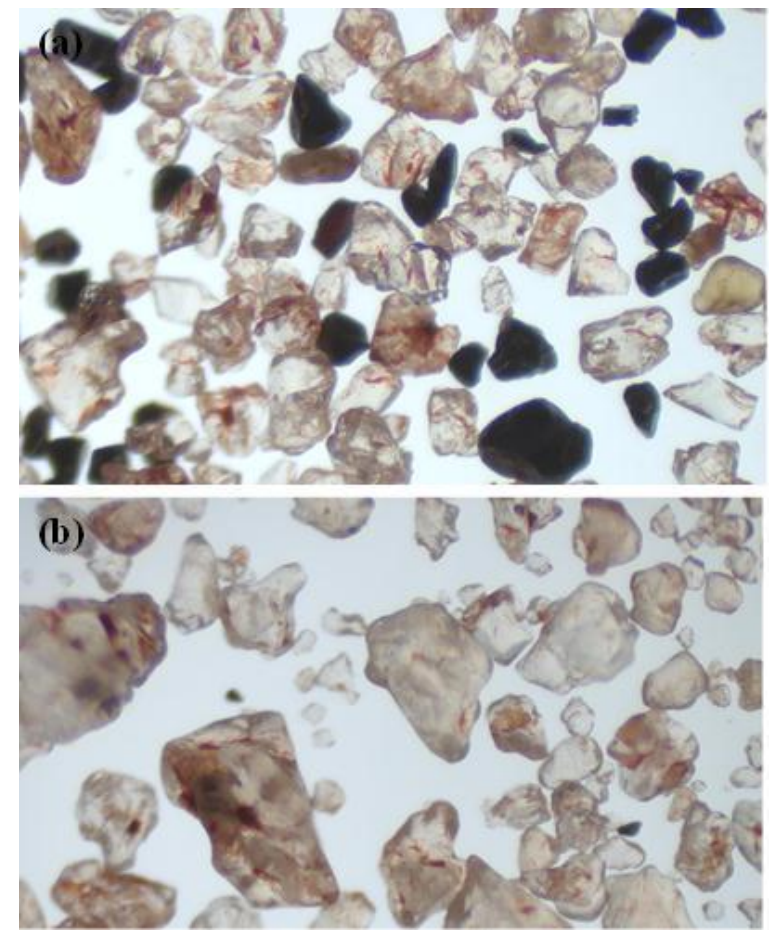

Fig. 8: a) moderately sorted red earth in Puttalam area, b) poorly sorted red earth in Mannar area $(1.5 \times 10)$

Further, the average Coefficient of uniformity $(\mathrm{Cu})$ and Coefficient of curvature $(\mathrm{Cc})$ (Tucker 2001) of RE of two areas, suggest that the Puttalam $\mathrm{RE}$ are poorly graded $(\mathrm{Cu}=2.6, \mathrm{Cc}=1)$ and Mannar $\mathrm{RE}$ are well graded $(\mathrm{Cu}=4.87$, $\mathrm{Cc}=1.3$ ) sediments. This possibly indicates the influence of different depositional or post depositional processes as well as the different sources of sediment supply for the formation of $\mathrm{RE}$ deposits in two regions studied.

\section{Grain Shape and Surface Features}

The surface morphology of quartz grains can be correlated with the mechanical energy and chemical processes that involved in different depositional environments (Itamiya et al., 2019, Dowdeswell et al., 2006). Quartz grains in Puttalam samples were more rounded (Fig. 9 a) than that of in Mannar samples (Fig. 10 a). Grain surfaces showed a dull appearance due to impact marks (Fig. 9 b). Further, disc-shaped concavities and v-shaped grooves were seen in quartz grains from Puttalam RE (Fig. 9 c, d ).
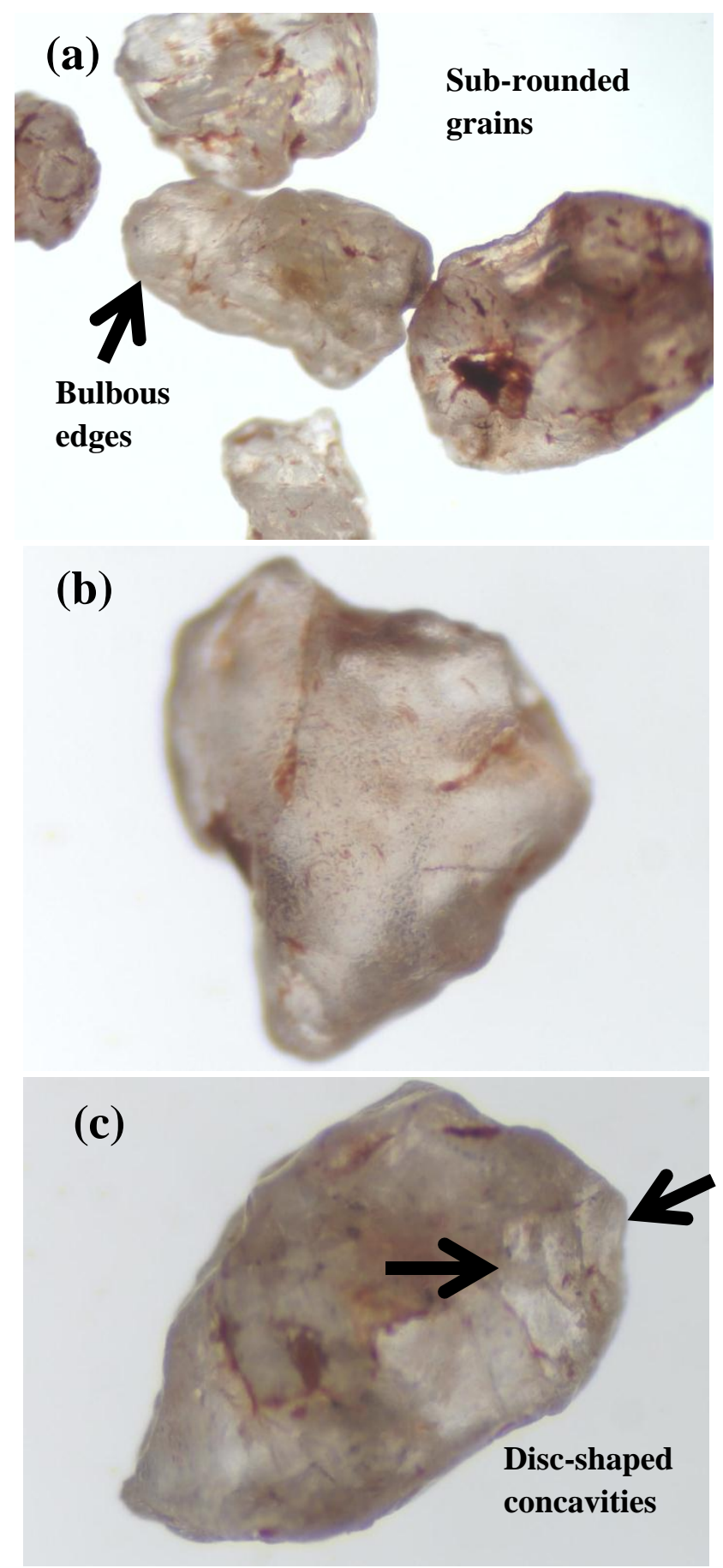

Fig. 9 Surface morphology of quartz grains in Puttalam RE; a) sub-rounded shape (4x10),b) dull surface with impact marks from abrasion (5.5x10), c) disc-shaped concavities (5.5 $\times 10)$ 


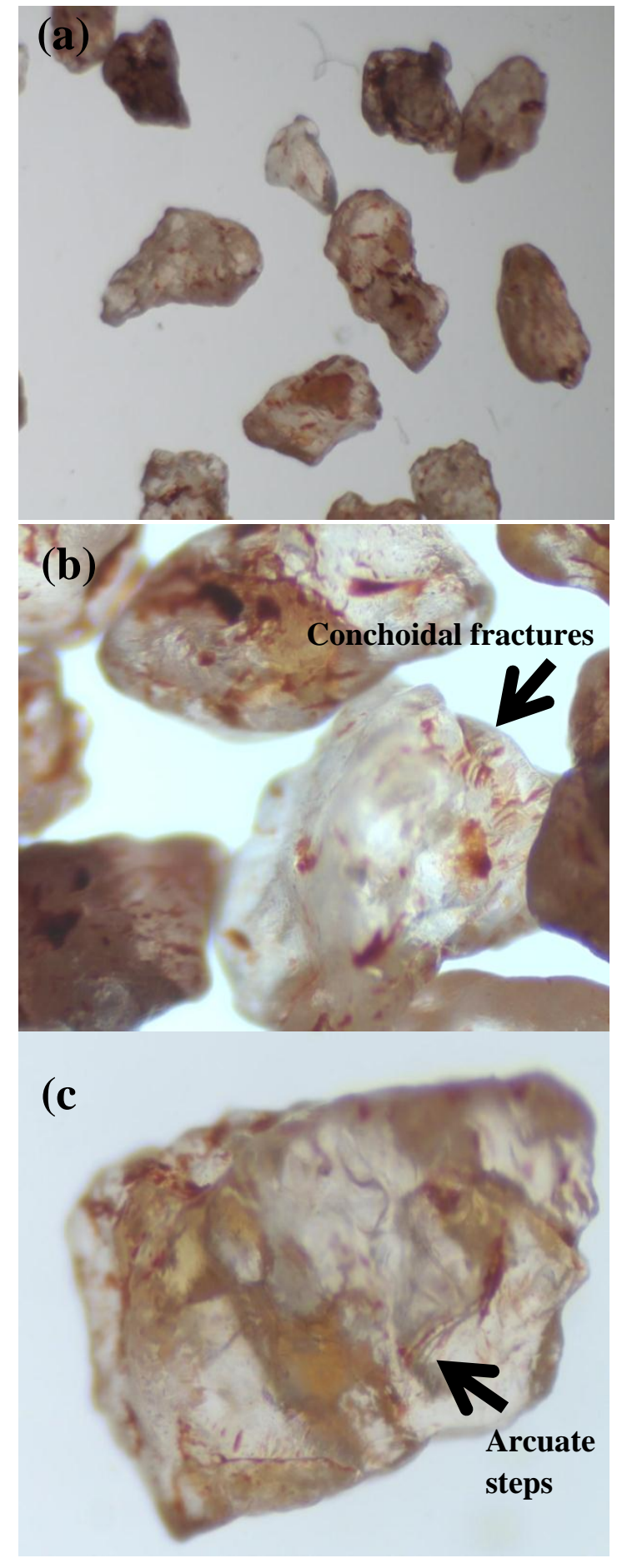

Fig. 10 Surface morphology of quartz grains in Mannar RE; a) sub-angular shape $(1.5 \times 10), b)$ conchoidal fractures $(5.5 \times 10), c)$ arcuate steps $(5.5 \times 10)$

Bulbous edges and dish-shaped concavities are index features of aeolian depositional environments (Mejia-Ledezma et al., 2020, Szerakowska et al., 2018, Woronko 2013). These observations supported aeolian origin of RE in Puttalam region as stated in previous studies (Dahanayake and Jayawardhane, 1979, Singhvi et al., 1986, Wallace et al., 2016).

In contrast, quartz in Mannar formations showed relatively less spherical shape (Fig. 10 a), more conchoidal fractures (Fig. $10 \mathrm{~b}$ ) and arcuate steps (Fig. $10 \mathrm{c}$ ). Conchoidal fractures and arcuate steps of quartz surface mostly resemble rapid deposition in high energy sub-aqueous environment such as delta and beaches (Itamiya et al., 2019, Mahaney and Kalm 2000, MejiaLedezma et al., 2020, Hossain et al., 2014). Therefore, Mannar RE formation might have be affected more by ocean waves compared to Puttalam RE, yet for a shorter period of time. The grains are not rounded possibly due to the influence of high energy environment over a shorter time period. Different sources of sediment could also influence the dissimilarities in the morphology of quartz grains of the two regions. Considering the proximity to the Indian subcontinent, Mannar RE formations may contain sediments transported from south India either by fluvial system or by wind in addition to drainages of Sri Lanka. The degree of roundness of fine sand in both Puttalam and Mannar samples was similar indicating the features of a dune environment

\section{CONCLUSIONS}

Red earth deposit in the northwestern coastal area is a unique geological formation in Sri Lanka. Even though it is appeared as a single unit throughout the area, the present study revealed that the mineralogical and chemical composition, grain size distribution and textural characteristics of the RE formation are varied in the studied two regions; Puttalam and Mannar. The thickness of the formation increases towards the west compared to the northern region along with higher magnetite, ilmenite and clay content consequently a higher amount of REEs. Grain morphology and related features observed in this study reveal the influence of fluvial, coastal and 
aeolian depositional processes in the formation of $\mathrm{RE}$ of both regions however to different extent. The west coast region shows features of dune sand, depicting the higher influence of aeolian processes in Puttalam RE. However, the larger quantities of heavy mineral associations observed in Puttalam RE indicate the possible influence of fluvial processes as well. In contrast, coarse quartz grains in Mannar region show features influenced by high energy sub-aqueous environment whereas fine quartz displays features of a dune environment. A detailed analysis of the aforementioned microstructural features is recommended using a scanning electron microscope, which has a higher depth of field to confirm the above conclusions. Further, a regional isotopic analysis of zircon grains in the entire RE deposit and Indian RE deposit would provide a good insight for the provenance analysis.

\section{ACKNOWLEDGMENTS}

Financial assistance from the Grant No. AHEAD/RA3/DOR/PDN/SCI/GEOLOGY/13 is highly acknowledged.

\section{REFERENCES}

Bernet M., Basset K. 2005. Provenance analysis by single quartz grain SEM-CL/optical microscopy. Journal of sedimentary research, 755 (3), 496-504.

Bheemlingeswara K., 1995. Possible effects of iron oxide coating in the recovery of particulate gold from stream sediments. Journal of Geochemical Exploration, 52- 3, 373-380.

Blott S.J., Pye K. 2001. GRADISTAT: A grain size distribution and statistics package for the analysis of unconsolidated sediments. Earth surface Processes and Landforms, 26 (11), 1237-1248.

Dahanayake K., Jayawardana S.K. 1979. Study of red and brown earth deposits if north-west Sri Lanka. Journal of Geological Society of India, 20 (9).
Dowdeswell J.A., Osterman L.E., Andrews J.T. 2006. Quartz sand grain shape and other criteria used to distinguish glacial and nonglacial events in a marine core from Frobisher Bay, Baffin Island, N.W.T., Canada. Sedimentology, 32 (1), 119-132.

Hossain H.M.Z., Tarek M., Armstrong-Altrin J.S., Monir M.M.U., Ahmed M.T., Ahmed S.I., Hernandez-Coronado C.J. 2014. Micro textures of detrital sand grains from the Cox's Bazar beach, Bangladesh: Implications for provenance and depositional environment. Carpathian Journal of Earth \& Environmental Sciences, 9 (3), 187-197.

Itamiya H., Sugita R., Sugai T. 2019. Analysis of the surface microtextures and morphologies of beach quartz grains in Japan and implications for provenance research. Progress in Earth and Planetary Science, 6:43.

Mahaney W.C., Kalm V. 2000. Comparative scanning electron microscopy study of oriented till blocks, glacial grains and Devonian sands in Estonia and Latvia. Boreas, 29, 3-51.

Mahatantila K., Seike Y., Okumura M. 2011. Adsorptive removal of lead (ii) ion using natural red earth from its iron and aluminum oxide forms. International Journal of Engineering Science and Technology, 3(2), 1655-1666.

Mahatantila K., Vithanage M., Seike Y., Okumura M. 2012. Adsorptive removal of cadmium by natural red earth: equilibrium and kinetic studies. Environmental Technology, 33(5), 597-606.

Mejia-Ledezma R.O., Zubillaga J.J.K., AlvarezSanchez L.F., Mendieta-Lora M., ArellanoTorres E., Tetlalmatzi-Martinez J.L., Gonzalez-Bermudez A., Patino-Andrade D., Armstrong-Altring J.S. 2020. Surface textures of quartz and ilmenite grains from dune and beach sand of the Gulf of Mexico coast, Mexico: Implications for fluvial, aeolian and marine transport. Aeolian Research, 45: 100611.

Nikagolla C., Chandrajith R., Weerassoriya R., Dissanayake C.B. 2013. Adsorption kinetics of chromium (iii) removal from aqueous solutions using natural red earth. 
Environmental Earth Sciences, 68 (3), 641645.

Panabokke C.R., 1996. Soils and agro-ecological environments of Sri Lanka. Natural Resources, Energy and Science Authority of Sri Lank, Natural Resources Series (2).

Pathberiya G.G., Jayasinghe G.Y., Chandrajith R. 2019. Adsorption kinetics if hexavalent chromium on to natural red earth: a laboratory simulated study. Water Science $\&$ Technology. Article in Press (doi:10.2166/wst.2019.351)

Rajapaksha A.U., Vithanage M., Jayarathna L., Kumara C.K. 2011. Natural red earth as a low cost material for arsenic removal: Kinetics and the effect of competing ions. Applied Geochemistry, 26 (4), 648-654.

Renaud K.M. 2014. The mineral industry of Sri Lanka. Mineral Year Book - Sri Lanka. United States Geological Survey

Reuter M., Harzhauser M., Piller W.E. 2020 Coastal landscape evolution in the Wilpattu National Park (NW Sri Lanka) linked to changes in sediment supply and rainfall across the Pleistocene-Holocene transition. Geological Journal, 1-15.

Singhvi A.K., Deraniyagala S.U., Sengupta D. 1986. Thermoluminescence dating of Quaternary red-sand beds: A case study of coastal dunes in Sri Lanka. Earth and Planetary Science Letters, 80, 139-144.

Sundararajan M., Srinivasalu S. 2010. Geochemistry of core sediments from Gulf of Mannar, India. International Journal of Environmental Research, 4 (4). 861-876.

Swan B. 1983. An introduction to coastal geomorphology of Sri Lanka. National Museum of Sri Lanka.

Szerakowska S., Woronko B., Sulewska M.J., Oczeretko E. 2018. Spectral method as a tool to examine microtextures of quartz sand-sized grains. Micron, 110, 36-45.

Tucker M.E. 2001. Sedimentary Petrology - 3rd Edition. Blackwell Publishing, India.

Vithanage M., Chandrajith R., Bandara A., Weerasooriya R. 2006. Mechanistic modeling of arsenic retention on natural red earth in simulated environmental systems. Journal of Colloid and Interface Science, 294 (2), 265-272.
Vithanage M., Chandrajith R., Bandara A., Weerasooriya R. 2007. Arsenic binding mechanisms on natural red earth: a potential substrate for pollution control. Science of the Total Environment, 379 (2-3), 244-248.

Wallace H. 2016. Geology of the PQ deposit, Sri Lanka. Applied Earth Science, 125 (3), 168173.

Woronko B., Giriat D., Losiak A., 2013. Micromorphology of quartz grains as a tool to recognize fluvial deposits on an example of field and experimental study. In: 10th International Conference on Fluvial Sedimentology, University of Leeds, UK. July 14-19, 2013. 